\title{
А.Г. Чернышов
}

\section{ЦИФРОВИЗАЦИЯ И ТЕХНОЛОГИЗАЦИЯ ОБЩЕСТВЕННОЙ ЖИЗНИ КАК СОЦИАЛЬНО- ПОЛИТИЧЕСКАЯ ПРОБЛЕМА: СОХРАНЕНИЕ ИДЕНТИЧНОСТИ И РОЛЬ ГОСУДАРСТВА В УСЛОВИЯХ РАЗВИТИЯ ГЛОБАЛЬНЫХ СЕТЕЙ}

\begin{abstract}
Проводится оченка различных мнений, которые в научной и экспертной среде отражают изменения в сфере глобальных сетевых и ичифровых технологий. Ставится задача доказать однобокость проведения «технологизации» и «цифровизаџии» общества вне осмысления роли культурных факторов развития самого человека. Делается вывод, что при выборе стратегии дальнейшего движения важно определиться с методологией понимания всей глубины новой циифровой эпохи, принять адекватные складывающимся реалиям политические и управленческие решения.

Ключевые слова: «циифровое» общество, глобальный гражданский экспертный форум, технократы, меритократия, искусственный интеллект, качественный контент.
\end{abstract}

Информационное общество погружает в свои глубины: Big Data, боты, мэмы становятся популярными терминами дня. Многие уловить до конца не могут смысла, а уже слово употребляется в контексте повседневной жизни. Затем стремительно начинает выходить из обихода и моды, когда на смену появляются новые термины и определения. Интернет-вещизм [1] обваливает на человека множество информационного «мусора». Возникает насущная проблема разобраться в том, как обеспечить качественный контент.

Начнем с «цифрового» сознания. Ряд авторов выдвигают тезис, что современная эпоха получает поколение «цифровых детей» с рождения, и сопротивляться данному процессу бессмысленно. На мозг «цифровых от рождения» так рано обрушивается вся мощь цифровых технологий, что на наших глазах вырастает «мозговой разрыв», пропасть между мышлением отцов и детей. По мнению авторов, сегодня «этот разрыв приобретает новые масштабы, и можно уже говорить про возникновение двух разных культур» [2. С. 15, 17].

Но что такое «цифровое» общество с точки зрения действительного отражения характеристик новой формации, а где всего лишь метафора? Беда, если родители всучили ребенку гаджет в первые дни жизни. В этом смысле человеческое сообщество морально и интеллектуально деградирует, покорно обменивая собственные способности на возможности электронных устройств. Другая проблема заключается в том, что те же компьютерные игры не оставляют простора воображению. Все ходы, костюмы и диалоги персонажей заранее спланированы разработчиками, и надо лишь выбрать из 3-4 вариантов. Фактически транснациональные корпорации через глобальные лифты и коррумпированных чиновников разных стран навязывают «новую виртуальную реальность», пытаются понудить жить в глобальной «цифре». 
Как следствие, появляется все больше детей с периферийным мышлением, лишенных сутевого восприятия действительности. А вот уже отсюда, развиваясь и приспосабливаясь к новым технологиям, мозг теряет базовые социальные навыки, происходит их угасание, социальное поведение ухудшается.

Управление с помощью информации (Ю. Хабермас) приобретает иной смысл: погружением и «растворением» человека в безбрежном информационном потоке и принуждением действовать в нем по заданному из какого-то штаба сценарию. У тех, кто держит вожжи управления социальными сетями и общественным сообществом, возникает соблазн построить глобальную цифровую диктатуру. Так удобнее и легче управлять большими массами людей по типу Big data. Человеку же, чтобы мало-мальски сохранить секрет, надо скрывать его от самого себя [3]. При этом зачастую введение ограничений в рамках национального сетевого сегмента диктуется тем, чтобы отгородиться от глобального диктата. Иная альтернатива - это налаживание реального диалога власти с обществом, поддержка и пестование настоящего местного самоуправления, делегирование полномочий домашним хозяйствам и выстраивание с ними равного и доверительного общения.

И в «доцифровых» обществах политическое управление было настроено на то, чтобы манипулировать сознанием и формировать его в тоталитарных рамках единообразия и усредненности [4]. «Цифровая» эпоха не может изменить генный код самого человеческого существа. Приоритеты родового человека остаются прежними: безопасность, питание, здоровье, самореализация. На подсознательном уровне в генетическом коде человека заложено творить: охотиться, преодолевать препятствия, достигать вершин. Как оценить результат своего труда при перемещении вороха бумаг в офисе или создании красивых презентаций? На что они повлияли? К какому осязаемому позитивному результату привели, кроме того, что каждый использованный бумажный лист привел к гибели очередного дерева или появилась еще одна корзина мусора? То же самое, если эти действия перевели в «цифру», в «виртуал».

Огромное количество жителей планеты живут на земле без всяких «цифровых» вещей, или минимальном пользовании ими, по потребности включиться в «продвинутый» мир. Но человек по большому счету настроен на получение конечного осязаемого результата (продукт человеческой деятельности). Это овеществленный труд: работа на земле, над реальным интеллектуальным продуктом. В него воплотились плоды труда, радость от достигнутого результата. Если этого нет, возникает подмена понятий, искажение и слом психики, мощнейшие мутации разума.

В итоге реальная действительность больше напоминает сюжеты из книги Джорджа Оруэлла из «1984», когда «Большой Брат» следит за вами везде и всегда. Получается, власти не только хотят все про всех знать, но и пытаются сохранить монополию на распространение информации (а сами стараются стереть свое негативное упоминание в сети путем законодательных норм, а электронные деньги, криптовалюту, использовать как новый виртуальный офшор, где под «электронным замком» прятать в транспарентном интернете свои накопления [5. С. 67].

Важнейший аспект в дискуссиях о сути и роли «цифрового» общества это осмысление интернета и цифрового мира как социального явления, его 
полезности и нужности для человека [6. С. 7]. В противном случае получаем технический прогресс, который начинает работать не для, а вопреки самому человеку. При такой постановке вопроса это будут лишь досужие обывательские рассуждения о «цифре»: о тотальном снижении себестоимости продукции, большей транспарентности мира, доступности и открытости технологий. Но не о том, куда пойдет безработный, когда ему на смену придут роботы [7]. Будет ли мир транспарентен для всех, когда уже сейчас создаются фактически закрытые криптовалюты и целые сегменты «теневого» интернета типа «Даркнет» [8. С. 116]. Киберденьги не будут принадлежать человеку физически. Это, вкупе с другими обстоятельствами, фактически означает крах так широко рекламируемой частной собственности и свободе личности как таковой. Да и вообще, не утратит ли в таком постиндустриальном мире человек свое прежнее значение и просто станет лишним [9. С. 23, 129], превратившись в некую биомассу с огромным «бесполезным классом» ненужных работников?

Технократические ловушки при выстраивании «цифрового» общества путем объявления самого технического прогресса ценностью мироздания уводят нас от столбовой дороги действительного культурного развития человеческого сообщества. Введение в оборот понятия «цифровой» экономики показывает, что цифровизация ведет к возрастанию роли нецифровых (аналоговых) услуг [10]. Искусственная технологизация мира - это окончательное закрепление его в рамках глобального ростовщическо-манипуляционного варианта развития. Раздаются аллилуйя «золотому» веку «цифры» [11], но отсутствует критический анализ самого глобального явления, охватывающего человеческий социум.

Важен акцент на фундаментальность образования, чтобы не упустить целостность и универсальность картины мира, который усложняется, «сохранить ориентацию на изучение глубинных закономерностей жизни (человека, природы и общества) и избежать зависимости от конъюнктурных знаний и умений» [12]. Социальные технологии должны получить неоспоримое первенство над всеми остальными. Пока же они остаются втуне. Преобладают «эффективные» менеджеры и технократы как циничные управленцы, лишенные всяких нравственных рефлексий. Некий набор установок типа Эджайл как попытка воспитать технократов в режиме закрытой секты, но при этом присвоить им право быть меритократами. То есть самыми мудрыми и достойными [13].

Самая востребованная специальность в мире - программист. За внешней понятностью такой тенденции стоят сложные процессы, доказывающие, что программисты зачастую пишут мир «под себя»: он просто «не думал о человеке, не пытался ставить себя на его место» [14. С. 35], так как понимает его по-своему, на ему только ведомом языке программирования. Каким окажется язык будущего при таком развитии событий, когда социальное пространство заполнит программно-цифровая «Матрица»? Технологии блокчейн ${ }^{1}$ претен-

\footnotetext{
${ }^{1}$ Блокчейн (англ. Blockchain или block chain) - система передачи информации, выстроенная по определённым правилам непрерывная последовательная цепочка блоков. Применение шифрования гарантирует, что пользователи могут изменять только те части цепочки блоков, которыми они «владеют» в том смысле, что у них есть закрытые ключи, без которых запись в файл невозможна.
} 
дуют на роль универсального гаранта исполнения взятых на себя обязательств. Но это фактически отмена основной функции государства! Это может привести к формированию «понятийного рынка», который окажется под контролем узкой группы лиц и криминального мира» [15].

Технологический детерминизм в качестве основополагающей причины социальных изменений не применим, так как из него выпадает живой человек со своими эмоциями, иррациональным мышлением и духовной сферой. В программно-технологической части «цифрового» мира идет архитектурная эволюция Интернета, перманентная и бесконечная [16. С. 13]. Эксперты спорят, что Интернет Вещей - это не просто «умный дом», а принципиально иное антропологическое пространство [17. С. 5, 15]. Однако значительно важнее сейчас оценить гуманитарную емкость сети и цифры, ее ценностные и смысловые основания.

С точки зрения социально-политической практики важно использование общественно полезного позитивного потенциала гражданского общества, находящегося в сети, согласованного с деятельностью реформирующейся системы государственного управления [18. С. 76]. «Электронная демократия» возможна при условии четких и прозрачных правил для всех его пользователей, без купюр и изъятий [19]. Сервисы типа «Активный гражданин» могут стать инструментом в реализации конституционных прав граждан. При условии фактически узаконенного референдума в сети, когда при сборе определенного количества голосов, наступает обязательность для власти исполнения электронной воли граждан. Иначе - это лишь срез настроений в обществе, еще хуже - «демократическая» игрушка. При такой конструкции реальную свободу в «цифре» человеку не получить. Это будет лишь иллюзия раба нового мирового порядка, принесшего себя в жертву ради торжества глобального цифрового общества завтрашнего дня [20]. Стал большим Хайпом $^{1}$ в сети. То есть мысли людей не накапливают знания, а превращаются в «шум».

Стоит задача «восстановить ценностно-рациональный мир, соединить ценностно-рациональные и целерациональные сферы общественной жизни». Пока же именно «рациональность техники повсеместно проникла в управление социальными процессами и в управление массовым сознанием» [21. C. $425,427,509-511]$.

Еще только предстоит определить смысловое содержание сетевого будущего. Создать Образ будущего вместе, используя и формируя сетевое интегральное мироустройство [22. С. 126-128], оценивая, действительно ли «подключенный» мир означает лучший [23. С. 34].

Важно не просто принять за данность, что в современном обществе люди становятся более зависимыми от информации. Нужно в максимальной степени снизить «эпидемию» информационной аномии в сети - процесса, когда сообщение, имеющее определенный смысл, в момент передачи информации, искажает, замещает или теряет этот смысл, создается множественность вариантов понимания, что приводит к имитации реального смысла, иллюзии реальности [24. С. 5]. А если еще и заведомо рукотворно создают фейковую

\footnotetext{
${ }^{1}$ Хайп - неол., сленг - шумиха в средствах массовой информации.
} 
среду, как человеку разобраться в потоке информации, сделать адекватные реальности выводы и принять решения к действию. Аномия как крах традиционных устоев, отклонение в системе социальных норм ведет к разрушению единства культуры.

Чтобы разобраться в нужном сетевом знании и не попасть в расставленные там же информационные ловушки, необходимо наличие высокого уровня критического мышления. Оно вырастает из фундаментального образования. Того, которое учит не техническим навыкам посредством образовательной услуги: «Если образование - это о том, как включить кофеварку, то это другое» [25]. Современное образование в режиме он-лайн, куда все больше перетекает знание, должно в своей первооснове содержать смыслы и стратегии духовного развития человека с учетом восстановления целостности личности. Более того, переходя на «цифровой» язык общения, важно не утерять носителей родословной языковой составляющей. Тут важна роль государства и различных гражданских институтов, которые должны добиваться соблюдения в интернет-коммуникациях норм речи [26. С. 134] и знать психологию сети [27. С. 4, 337].

Смайлово-лайковое пространство не дает оснований для развития человеческих способностей. А знания могут не только наращиваться, но и убывать. Особенно если теряется потребность в кристаллизации ценностносмысловых начал. Если не принимать во внимание всякие нюансы и детали, не видеть полутона, то можно скатиться к стандартизации и примитивизации всей общественной жизни. Эта примитивизация «исторической политики» и современного взгляда на жизнь как статичная красивая виртуальная картинка. Тут и до варваризации недалеко с возвращением архаики и отсталости, а по сути дела - наступления времен мракобесия. Примеров «падения знания» в истории человечества множество. Одно из них - разрушение крупнейшего в Античном мире интеллектуального и образовательного центра - Александрийской библиотеки, существовавшей с III века до н.э до IV века н.э.

Новое поколение фальшивого контента стало возможным в том числе благодаря генеративным нейросетям, неподконтрольному развитию НЛП [28] и развивается в режиме глобальных кибервойн нового поколения [29]. Что может стать препятствием повторения такого варварства сегодня уже в глобальном масштабе? Это формирование понятийного мышления [30], способного встать на пути несистемному знанию, тем самым оградив человека от попадания в состояние когнитивного диссонанса ${ }^{1}$. Возможность сохранить книжно-бумажную культуру.

Крайне важно расширение качественного контента посредством формирования разных системных информационно-аналитических платформ. Причем с прогнозированием того, как будет развиваться сеть в краткосрочной и долгосрочной перспективе. Выстраивая системные платформы более высокого интеллектуального уровня с учетом мнения и интересов граждан. Что сейчас? Социальная сеть «ВКонтакте» - нахождение на постоянной связи для обмена текущими новостями, «Фейсбук» (лицо в книге) - выставление собст-

${ }^{1}$ Когнитивный диссонанс - состояние психического дискомфорта индивида, вызванное столкновением в его сознании конфликтующих представлений: идей, верований, ценностей или эмоциональных реакций. 
венного лица и события на фоне происходящих изменений, а также обмен информацией среди круга «друзей». «Твиттер» (болтать) - для публичного обмена короткими сообщениями и актуальными новостями. «Инстаграм» обмен фотографиями (селфи) и видео. «Телеграмм» - обмен текстовыми сообщениями и медиафайлами разных форматов. Возникает потребность в создании архивов интеллектуальной памяти глобального масштаба, где каждый гражданин смог бы оставить важную информацию, поделиться своими мыслями, погрузиться в нужную ему структурированную информацию. Интеллектуальные поисковые возможности и аналитические сервисы реально могут привести к созданию на горизонтальном уровне Глобального экспертного гражданского форума - TEXTOGRAM, за которым, как представляется, будущее. Он фактически сможет стать и фиксатором авторства идей того или иного человека, когда одномоментно в Интернете будет отражаться та или иная новация или открытие. Такой фонд сможет стать информационным резервуаром по аккумулированию ведущих мировых экспертов и лучших практик, в том числе и социальных.

Пока же современное «цифровое» общество развивается хаотично и несистемно. Такая модель приводит к размыванию интеллектуальной и нравственной платформы общества. Уходят накопленные знания, так как умирает его носитель. Контент становится скудным: повторяемость «прописных истин» и понятий, которые в современных условиях перестают действовать. Людям приходится вылавливать и систематизировать нужные истинные знания по крупицам. И что будет анализировать искусственный интеллект [31. C. 428]? Каких опасностей мы сможем избежать, следя за развитием искусственного интеллекта в настоящем [32. С. 226]?

Смысловое наполнение информационных интернет-ресурсов способно приостановить наблюдающуюся атомизацию человека в сети. Сегодня Интернет лишил многих личного общения. Но парадокс состоит в том, что анонимность в сети скоро надоедает, и за ней возникает обратная волна - показать себя, высказать своё мнение о наболевшем. Сегодня мир переживает очередную революцию - революцию социальных данных. В самом широком смысле понятие «социальные данные» относится к той личной информации, которую выкладывают и которой делятся пользователи Интернета. С точки зрения накопления точек роста нового знания явно происходит что-то существенное, причем зачастую вне поля зрения конкретной власти, которая мыслит прежними клише при оценке развития общества [33].

При этом, перенося технологии «сарафанного радио» и обсуждения последних новостей на свой кухне в глобальную сеть, фактически возвращаемся к «деревенскому» укладу: каждый знает практически все про жителя деревни. Это ведет к тому, что любому чиновнику будет сложно удержать в секрете свой дворец. Но и обычному жителю с приватностью и сохранением своей личной жизни будет тяжелее. Значит, еще только предстоит научиться жить в «глобальной деревне». При этом не скатиться к «глобальной пещере» и первобытному варварству.

«Цифровое» общество нужно рассматривать как шаг к формированию нового типа взаимоотношений власти и общества, построенного на нравственных принципах управления, с точки зрения понятийно-ценностной плат- 
формы и методологии общения с гражданами, без границ и излишних бюрократических надстроек, со стратегией сохранения уклада коренных народов, их идентичности. Без политики распыления людей по миру, лишающей родства, корней и гражданства. Как высшая форма объединения индивидуумов [34. С. 178-179] с устойчивыми цивилизационными кодами, интеллектуально-технологическим и культурным суверенитетом.

Непомерное восхищение «цифрой» приводит к некритическому отношению к возможным последствиям «цифровизации» всей общественной жизни для естественной локальной жизни самого человека, оторвавшегося от земли.

\section{Лuтература}

1. Зараменских Е.П. Интернет вещей. Исследования и область применения. М.: Инфра-М, 2017. $188 \mathrm{c}$.

2. Смолл Г., Ворган Г. Мозг онлайн. Человек в эпоху интернета. М.: КоЛибри, 2011. 352 с.

3. Ковачич Л. «Большой брат» 2.0. Как Китай строит цифровую диктатуру [Электронный pecypc] // Московский центр Карнеги: сайт. Электрон. дан. 18.07.2017. URL: http://carnegie.ru/commentary/71546 (дата обращения: 06.07.2017).

4. Щербинин А.И. Тоталитарная индоктринация как управление сознанием: учеб. пособие. Томск: Изд-во Том. ун-та, 2012. 274 с.

5. Солдатов А., Бороган И. Битва за Рунет. Как власть манипулирует информацией и следит за каждым из нас. М.: Альпина Паблишер, 2017. 342 с.

6. Мирошников Б.Н. Сетевой фактор. Интернет и общество. М.: Кучково поле, 2015. 284 с.

7. Гордеев А. Лишние люди XXI века. Как роботы оставят без работы «синих» и «белых» воротничков. «РБК daily», [Электронный ресурс] // РБК : информационный портал. Электрон. дан. 19.01.2017. URL: http://www.rbc.ru/newspaper/2017/01/20/58806fe19a794712678e210e (дата обращения: 16.06.2017).

8. Бартлетт Дж. Подпольный интернет. Темная сторона мировой паутины. М.: Эксмо, 2016. $352 \mathrm{c}$.

9. Harari Y. Homo Deus: A Brief History of Tomorrow. Harper, 2017. 528 p.

10. Славин Б. Спектакль о цифровизации России [Электронный ресурс] // Ведомости : сайт. Электрон. дан. 12.07.2017. URL: https://www.vedomosti.ru/opinion/articles/2017/07/12/720652spektakl-tsifrovizatsii (дата обращения: 13.07.2017).

11. Грамматчиков А., Гурова Т. Золотой век "цифры". Наступает // Эксперт. 2017. № 3033. 24 июля - 20 августа. С. 10-15.

12. Галажинский Э. Чему не учат в университетах [Электронный ресурс] // Ведомости :сайт. Электрон. дан. 2017, 3 августа URL: https://www.vedomosti.ru/opinion/articles/2017/ 08/03/727760-ne-uchat-v-universitetah (дата обращения: 05.08.2017).

13. Симонов $K$. Продвижение технократов. Меритократия как замена идеологии [Электронный ресурс] // Ведомости: сайт. Электрон. дан. 25.07.2017. URL: https://www. vedomosti.ru/opinion/columns/2017/07/25/725687-prodvizhenie-tehnokratov (дата обращения: 01.08.2017).

14. Моисеев B. Время великого Нерда [Электронный ресурс] // Русский репортер. 2014. № 34. 04-11 сентября. Электрон. версия печат. публ. URL: http://www.rusrep.ru/ article/2014/09/04/vremya-velikogo-nerda (дата обращения: 10.08.2017).

15. Тихонов А. Мир по цифровым понятиям [Электронный ресурс] // Наша Версия. 2017. № 29. 31.07. Электрон. версия печат. публ. URL: https://versia.ru/kurs-bitkoina-obrushivayutspecsluzhby (дата обращения: 10.08.2017).

16. Робачевский А. Интернет изнутри: экосистема глобальной сети. М.: Альпина Паблишер, 2017. $271 \mathrm{c}$.

17. Чеклецов B.B. Чувство планеты: Интернет Вещей и следующая технологическая революция. М.: Российский исслед. центр по Интернету Вещей, 2013. 130 с.

18. Модели диалога власти и общества в интернет-коммуникациях. М.: Проспект, 2016. 112 с.

19. Акопов Г.Л. Интернет и политика: модернизация политической системы на основе инновационных политических интернет-коммуникаций. М.: КноРус, 2017. 238 с. 
20. Дробницкий Д. Исторический «кухонный спор» об образе будущего [Электронный ресурс] // Взгляд. Деловая газета : сайт. Электрон. дан. 24.07.2017. URL: https://vz.ru/columns/2017/7/24/879863.print.html (дата обращения: 11.08.2017).

21. Федотова В.Г., Колпаков В.А., Федотова Н.Н. Глобальный капитализм: три великие трансформации. М.: Культурная революция, 2008. 608 с.

22. Цаголов Г.Н. Новое интегральное общество - седьмая формация // Новое интегральное общество: общетеоретические аспекты и мировая практика. М.: Ленанд, 2016. 352 с.

23. Грингард С. Интернет вещей: будущее уже здесь. М.: Точка, 2017. 198 с.

24. Карпова А.Ю. Информационная аномия в политической коммуникации : автореф. дис. ... д-ра социол. наук. М., 2017. 46 с.

25. Черниговская T. «Все человечество спятило» [Электронный ресурс] // Пси-фактор: сайт. Электрон. дан. 07.05.2017. URL: http://psifactor.info/ed/tatyana-chernigovskaya-vsechelovechestvo-spyatilo.htm (дата обращения: 11.07.2017).

26. Интернет-коммуникация как новая речевая формация. М.: Флинта: Наука, 2016, 323 с.

27. Носов Н.А. Виртуальная психология. М.: Аграф, 2000. 432 с.

28. Толкачев С.Ф. Интернет будущего. Нейронное программирование диалоговых систем. М.: Корона. Век, 2017. 191 с.

29. Коровин В. Третья мировая сетевая война. СПб.: Питер, 2014. 352 с.

30. Ясюкова Л.А. Меньше $20 \%$ людей обладают полноценным понятийным мышлением [Электронный ресурс] // Econet: портал. Электрон. дан. URL: https:/econet.ru/articles/116494lyudmila-yasyukova-menshe-20-lyudey-obladayut-polnotsennym-ponyatiynym-myshleniem (дата обращения: 11.07.2017).

31. Рассел С. Искусственный интеллект: современный подход. М.: Вильямс, 2017. 1407 с.

32. Бостром Н. Искусственный интеллект. Этапы. Угрозы. Стратегии. М.: Манн, Иванов, Фербер, 2016. $491 \mathrm{c.}$

33. Вейгенд A. Революция XXI века [Электронный ресурс] // Известия. Iz.ru: портал. Электрон. дан. 09.11.2016. URL: http://izvestia.ru/news/643563\#ixzz4RwIaMX2q (дата обращения: 11.05.2017).

34. Хапров С. Цифровой коммунизм. М.: МФПУ «Синергия», 2013. 184 с.

Alexey G. Chernyshov. Financial University under the Government of the Russian Federation (Moscow, Russian Federation)

E-mail: ag555@mail.ru

DOI: $10.17223 / 1998863 X / 40 / 30$

THE DIGITALIZATION AND TECHNOLOGIZATION OF SOCIAL LIFE AS A SOCIOPOLITICAL PROBLEM: THE PRESERVATION OF THE IDENTITY AND ROLE OF THE STATE IN THE DEVELOPMENT OF GLOBAL NETWORKS

Key words: digital society, global civil panel of experts, technocrats, meritocracy, artificial intelligence, quality content

The relevance of this topic is determined by the rapid processes of digitalization and technologization of modern society. However, there is an urgent problem to understand how to provide quality content. To make information technology really became the basis of social environment that would have grown out of cultural and conceptual factors of human development itself. The main problem is not how to as quickly as possible to be able to adapt to new realities. First, it is important to understand what global shifts in human society happen and why. What changes are man-made and therefore subjective and influenced by specific individuals and which objective. Can citizens, and to what extent, to influence these changes and where to direct its main movement and energy. For understanding contemporary reality required to reflect the most important moments of the events that are yet to give answers. So, what happens to the human community at mass, and in some ways even total, the use of digital technologies? Why you need a man these digital technologies, robotics, artificial intelligence, if the man withdraws in a virtual world, if they were being squeezed out of the social space of man himself, the Creator, make it more dependent on "machines" and the external manipulation of consciousness? The concept of "Information society" is not identical to the term "knowledge Society". Between them it is impossible to equate, as do many scientists and experts, Handle information flow much easier. Effective tools for preparation of information became available to almost everyone. But quality of content has not increased. The most important aspect in discussions about the nature and role of the digital society - is, above all, understanding of the Internet and the whole digital world from the point of view of social phenomena, from the point of view of utility and usefulness to humans. Otherwise we 
get technical progress, which starts to work not so much for how much contrary to the person. Classic phrase, that progress cannot be stopped, gets an ominous sound, obessmyslivaet at all for a person need participate in some creative for him personally change.

\section{References}

1. Zaramenskikh, E.P. (2017) Internet veshchey. Issledovaniya i oblast' primeneniya [Internet of things. Research and field of application]. Moscow: Infra-M.

2. Small, G. \& Worgan, G. (2011) Mozg onlayn. Chelovek v epokhu internet [iBrain: Surviving the Technological Alternation of the Modern Mind]. Translated from English by B. Kozlovsky. Moscow: KoLibri.

3. Kovachich, L. (n.d.) "Bol'shoy brat" 2.0. Kak Kitay stroit tsifrovuyu diktaturu ["Big Brother" 2.0. How China builds a digital dictatorship]. [Online] Available from: http://carnegie.ru/commentary/71546. (Accessed: 6th July 2017).

4. Shcherbinin, A.I. (2012) Totalitarnaya indoktrinatsiya kak upravlenie soznaniem [Totalitarian indoctrination as control of consciousness]. Tomsk: Tomsk State University.

5. Soldatov, A. \& Borogan, I. (2017) Bitva za Runet. Kak vlast' manipuliruet informatsiey i sledit za kazhdym iz nas [The Battle for the Runet. How power manipulates information and monitors each of us]. Moscow: Al'pina Pablisher.

6. Miroshnikov, B.N. (2015) Setevoy faktor. Internet i obshchestvo [The network factor. Internet and society]. Moscow: Kuchkovo pole.

7. Gordeev, A. (2017) Lishnie lyudi XXI veka. Kak roboty ostavyat bez raboty "sinikh" $i$ "belykh" vorotnichkov [Superfluous people of the 21 st century. As robots leave the "blue" and "white" collars without work]. [Online] Available from: http://www.rbc.ru/newspaper/2017/01/20/ 58806fe19a794712678e210e. (Accessed: 16th June 2017).

8. Bartlett, J. (2016) Podpol'nyy internet. Temnaya storona mirovoy pautiny [The Dark Net: Inside the Digital Underworld]. Translated from English by M. Raitman. Moscow: Eksmo.

9. Harari, Y. (2017) Homo Deus: A Brief History of Tomorrow. Harper.

10. Slavin, B. (2017) Spektakl' o tsifrovizatsii Rossii [Performance on the digitalisation of Russia]. [Online] Available from: https://www.vedomosti.ru/opinion/articles/2017/07/12/720652-spektakltsifrovizatsii. (Accessed: 13th July 2017).

11. Grammatchikov, A. \& Gurova, T. (2017) Zolotoy vek "tsifry". Nastupaet [The Golden Age of Digitalisation. Coming]. Ekspert. 30-33. pp. 10-15.

12. Galazhinskiy, E. (2017) Chemu ne uchat v universitetakh [What is not taught in universities]. [Online] Available from: https://www.vedomosti.ru/opinion/articles/2017/08/03/727760-ne-uchat-vuniversitetah. (Accessed: 5th August 2017).

13. Simonov, K. (2017) Prodvizhenie tekhnokratov. Meritokratiya kak zamena ideologii [Promotion of technocrats. Meritocracy as a substitute for ideology]. [Online] Available from: https://www.vedomosti.ru/opinion/columns/2017/07/25/725687-prodvizhenie-tehnokratov. (Accessed: 1st August 2017).

14. Moiseev, V. (2014) Vremya velikogo Nerda [The time of the great Nerd]. Russkiy reporter. 34. [Online] Available from: http://www.rusrep.ru/article/2014/09/04/vremya-velikogo-nerda. (Accessed: 10th August 2017).

15. Tikhonov, A. (2017) Mir po tsifrovym ponyatiyam [The World of Digital Concepts]. Nasha Versiya. 29. [Online] Available from: https://versia.ru/kurs-bitkoina-obrushivayut-specsluzhby. (Accessed: 10th August 2017).

16. Robachevskiy, A. (2017) Internet iznutri: ekosistema global'noy seti [The Internet from the inside: the ecosystem of the global network]. Moscow: Al'pina Pablisher.

17. Chekletsov, V.V. (2013) Chuvstvo planety: Internet Veshchey $i$ sleduyushchaya tekhnologicheskaya revolyutsiya [The feeling of the planet: Internet of things and the next technological revolution]. Moscow: Rossiyskiy issled. tsentr po Internetu Veshchey.

18. Vasilenko, L., Kazantseva, O., Vasilenko, N. \& Tarasova, E. (2016) Modeli dialoga vlasti $i$ obshchestva $v$ internet-kommunikatsiyakh [Models of dialogue between government and society in Internet communications]. Moscow: Prospekt.

19. Akopov, G.L. (2017) Internet i politika: modernizatsiya politicheskoy sistemy na osnove innovatsionnykh politicheskikh internet-kommunikatsiy [Internet and politics: modernisation of the political system on the basis of innovative political Internet communications]. Moscow: KnoRus. 
20. Drobnitskiy, D. (2017) Istoricheskiy “kukhonnyy spor” ob obraze budushchego [Historical "kitchen dispute" about the image of the future]. [Online] Available from: https://vz.ru/columns/2017/7/24/879863.print.html. (Accessed: 11th August 2017).

21. Fedotova, V.G., Kolpakov, V.A. \& Fedotova, N.N. (2008) Global'nyy kapitalizm: tri velikie transformatsii [Global capitalism: three great transformations]. Moscow: Kul'turnaya revolyutsiya.

22. Tsagolov, G.N. (2016) Novoe integral'noe obshchestvo - sed'maya formatsiya [The new integral society of the seventh formation]. In: Bogomolov, O. et al. Novoe integral'noe obshchestvo: obshcheteoreticheskie aspekty i mirovaya praktika [New Integral Society: General Theoretical Aspects and World Practice]. Moscow: Lenand.

23. Gringard, S. (2017) Internet veshchey: budushchee uzhe zdes' [Internet of things: the future is already here]. Moscow: Tochka.

24. Karpova, A.Yu. (2017) Informatsionnaya anomiya v politicheskoy kommunikatsii [Information anomie in political communication]. Abstract of Sociology Cand. Diss. Moscow.

25. Chernigovskaya, T. (n.d.) "Vse chelovechestvo spyatilo" [All of humanity is crazy]. [Online] Available from: http://psifactor.info/ed/tatyana-chernigovskaya-vse-chelovechestvo-spyatilo.htm. (Accessed: 11th July 2017).

26. Kolokoltsev, T.N. \& Lutovinov, O.V. (eds) (2016) Internet-kommunikatsiya kak novaya rechevaya formatsiya [Internet communication as a new speech formation]. Moscow: Flinta: Nauka.

27. Nosov, N.A. (2000) Virtual'naya psikhologiya [Virtual psychology]. Moscow: Agraf.

28. Tolkachev, S.F. (2017) Internet budushchego. Neyronnoe programmirovanie dialogovykh system [Internet of the future. Neural programming of interactive systems]. Moscow: Korona. Vek.

29. Korovin, V. (2014) Tret'ya mirovaya setevaya voyna [The Third World Web War]. St. Petersburg: Piter.

30. Yasyukova, L.A. (n.d.) Men'she $20 \%$ lyudey obladayut polnotsennym ponyatiynym myshleniem [Less than $20 \%$ of people have full-fledged conceptual thinking]. [Online] Available from: https://econet.ru/articles/116494-lyudmila-yasyukova-menshe-20-lyudey-obladayut-polnotsennymponyatiynym-myshleniem. (Accessed: 11th July 2017).

31. Russell, S. (2017) Iskusstvennyy intellekt: sovremennyy podkhod [Artifical Intelligence: A Modern Approach]. Translated from English by K. Ptitsyn. Moscow: Vil'yams.

32. Bostrom, N. (2016) Iskusstvennyy intellekt. Etapy. Ugrozy. Strategii [Artificial Intelligence. Stages. Threats. Strategies]. Moscow: Mann, Ivanov, Ferber.

33. Weigend, A. (2016) Revolyutsiya XXI veka [Revolution of the 21st century]. [Online] Available from: http://izvestia.ru/news/643563\#ixzz4RwIaMX2q. (Accessed: 11th May 2017).

34. Khaprov, S. (2013) Tsifrovoy kommunizm [Digital Communism]. Moscow: Sinergiya. 